\title{
Pediatric Outcome after Maternal Cancer Diagnosed during Pregnancy
}

\author{
F. Amant, T. Vandenbroucke, M. Verheecke, M. Fumagalli, M.J. Halaska, \\ I. Boere, S. Han, M.M. Gziri, F. Peccatori, L. Rob, C. Lok, P. Witteveen, \\ J.-U. Voigt, G. Naulaers, L. Vallaeys, F. Van den Heuvel, L. Lagae, \\ L. Mertens, L. Claes, and K. Van Calsteren, for the International Network \\ on Cancer, Infertility, and Pregnancy (INCIP)
}

\section{ABSTRACT}

\section{BACKGROUND}

Data on the long-term outcome of children who are exposed to maternal cancer with or without treatment during pregnancy are lacking.

\section{METHODS}

In this multicenter case-control study, we compared children whose mothers received a diagnosis of cancer during the pregnancy with matched children of women without a cancer diagnosis. We used a health questionnaire and medical files to collect data regarding neonatal and general health. All children were prospectively assessed (by means of a neurologic examination and the Bayley Scales of Infant Development) at 18 months, 36 months, or both. A cardiac assessment was performed at 36 months.

RESULTS

A total of 129 children (median age, 22 months; range, 12 to 42) were included in the group whose mother had cancer (prenatal-exposure group) with a matching number in the control group. During pregnancy, 96 children $(74.4 \%)$ were exposed to chemotherapy (alone or in combination with other treatments), 11 (8.5\%) to radiotherapy (alone or in combination), 13 (10.1\%) to surgery alone, 2 (1.6\%) to other drug treatments, and 14 (10.9\%) to no treatment. Birth weight was below the 10th percentile in 28 of 127 children (22.0\%) in the prenatal-exposure group and in 19 of 125 children $(15.2 \%)$ in the control group $(\mathrm{P}=0.16)$. There was no significant betweengroup difference in cognitive development on the basis of the Bayley score $(\mathrm{P}=0.08)$ or in subgroup analyses. The gestational age at birth was correlated with the cognitive outcome in the two study groups. Cardiologic evaluation among 47 children at 36 months of age showed normal cardiac findings.

CONCLUSIONS

Prenatal exposure to maternal cancer with or without treatment did not impair the cognitive, cardiac, or general development of children in early childhood. Prematurity was correlated with a worse cognitive outcome, but this effect was independent of cancer treatment. (ClinicalTrials.gov number, NCT00330447.)

The authors' full names, academic degrees, and affiliations are listed in the Appendix. Address reprint requests to Dr. Amant at the Department of Gynecologic Oncology, University Hospitals Leuven, Herestraat 49, B-3000 Leuven, Belgium, or at frederic.amant@uzleuven.be.

Drs. Amant and Verheecke and Ms. Vandenbroucke contributed equally to this article.

This article was published on September 28, 2015, at NEJM.org.

DOI: 10.1056/NEJMoal508913

Copyright (c) 2015 Massachusetts Medical Society. 
F ETAL DEVELOPMENT IS A COMPLEX PROcess. At different stages of development, different aspects can be influenced by external factors (e.g., teratogenic drugs, alcohol, smoking, maternal stress, and altered nutrition). Among women in whom cancer is diagnosed during pregnancy, factors such as maternal illness, diagnostic tests, cancer treatment, and increased levels of maternal stress can negatively influence fetal development. Cancer treatment during pregnancy exposes the fetus to potentially toxic substances that influence cell division. Chemotherapeutic drugs can cross the placenta in varying amounts. ${ }^{1,2}$ Data on fetal effects of maternal cancer treatment are based mainly on retrospective cohort studies. ${ }^{3-6}$ From our 10-year experience, it appears that the limited availability of safety data can influence therapeutic decision making, which results in a high threshold for initiating chemotherapy and a low threshold for terminating pregnancy. It can also delay maternal treatment and result in preterm induction of labor. Limited data are also available on prenatal exposure to radiotherapy. ${ }^{7}$

Our group published combined prospective and retrospective data from a multicenter study involving children who had prenatal exposure to chemotherapy. Our initial data seemed to suggest that fetal exposure to maternal cancer treatments was not associated with cognitive or cardiac abnormalities. ${ }^{8}$ The combined retrospective and prospective design limited the interpretation of the results, since the findings from different tests at different ages (16.8 months to 17.6 years of age) were pooled. Therefore, we enlarged the prospective cohort to include only those in early childhood (12 to 42 months) and evaluated the general health status, growth, cognitive development, and cardiac structure and function and compared the results with those for children in a matched control group.

\section{METHODS}

\section{STUDY PARTICIPANTS}

This study is based on a collaboration between national referral centers in Belgium, the Netherlands, Italy, and the Czech Republic, all members of the International Network on Cancer, Infertility, and Pregnancy. Children in the prenatal-exposure group had mothers in whom cancer was diagnosed during pregnancy with or without treat- ment during pregnancy. Controls were children born to healthy mothers after uncomplicated pregnancies and deliveries. The study design and recruitment are summarized in Figure 1. The study protocol is available with the full text of this article at NEJM.org. For the cognitive developmental and general health examinations, control children were recruited in Belgium (for Belgium and the Netherlands), Italy, and the Czech Republic and were matched in a 1:1 ratio with respect to gestational age and age at testing with the children in the prenatal-exposure group in that particular country. Control children for the cardiac examinations were recruited in Belgium and Toronto and were matched in a 1:1 ratio for the age at testing and sex. Details regarding recruitment are provided in the Methods section in the Supplementary Appendix, available at NEJM.org. Written parental informed consent was provided for each child.

\section{STUDY TESTING}

We collected obstetric, perinatal (including congenital malformations), and oncologic data for each mother-child pair. We calculated birth-weight percentiles, considering the gestational age at birth, birth weight, sex, race or ethnic group, parity, and maternal height and weight when available. The fetal radiation dose was calculated according to the dose program Peridose developed by van der Giessen. ${ }^{9}$ From 2005 through 2011, we invited the children in the fetal-exposure group and the control group to participate in follow-up at the age of 18 months. From 2012 through 2015, children in the two groups were invited to participate at both 18 months and 36 months. For children who were tested at both 18 months and 36 months, we included only one result (the one for which a matched control was available) in the analysis. Clinical neurologic and general pediatric examinations were performed in all study children, and parents completed a health questionnaire (see the Methods section in the Supplementary Appendix).

We assessed the cognitive development of the children in the two groups using the Bayley Scales of Infant Development. Standard scores on this test range from 50 to 150 , with higher scores indicating more advanced development; the mean $( \pm S D)$ score is $100 \pm 15$, and a score of less than 85 indicates a developmental delay. ${ }^{10,11}$ The third edition (cognitive scale) was used in Italy, where- 


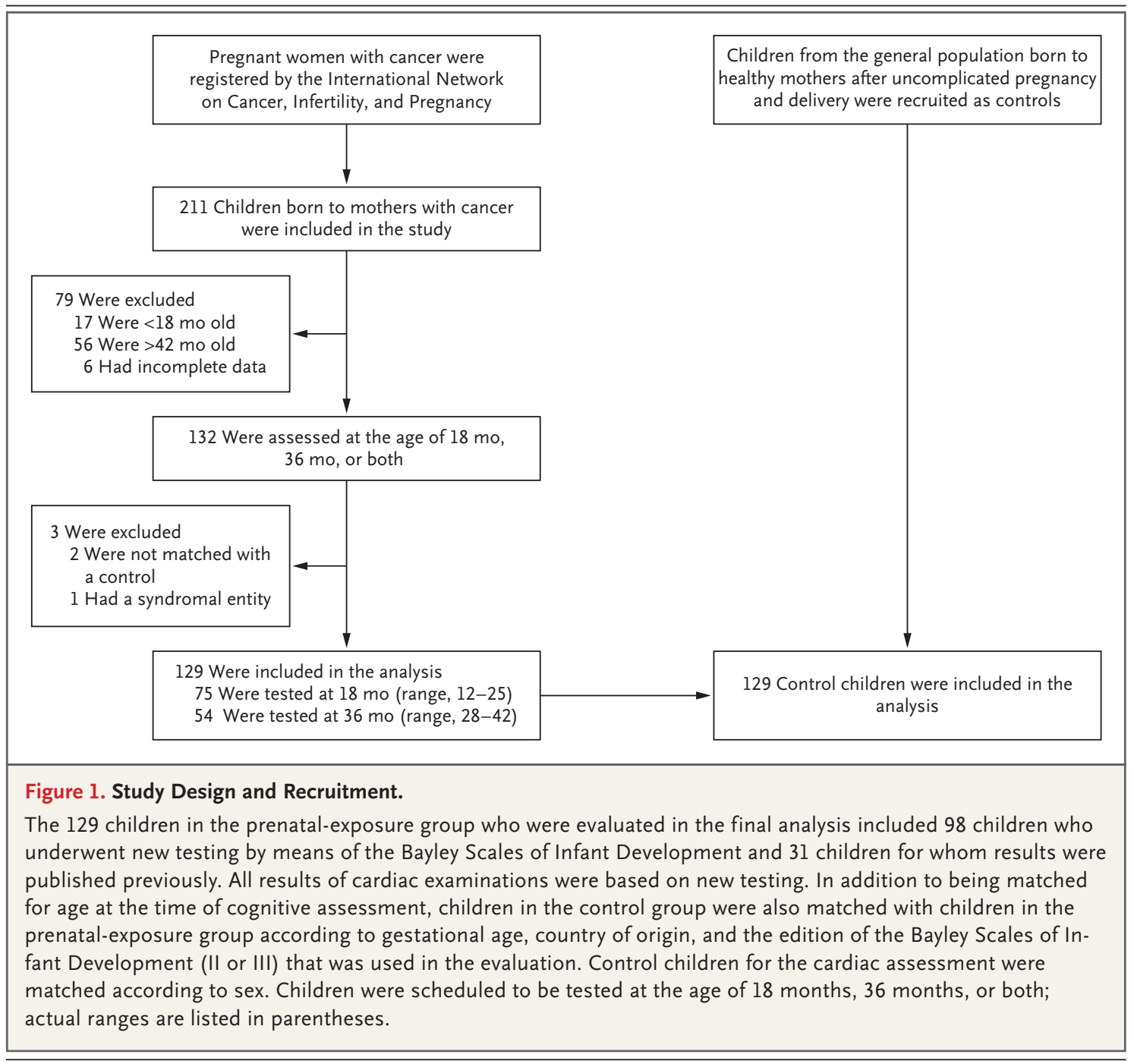

as the second edition (mental scale) was used in Belgium, the Netherlands, and the Czech Republic, according to the availability of the most recent edition at the start of inclusion. Bayley III cognitive scores were found to be significantly higher than Bayley II mental developmental index scores among both children who were born at term and those who were born preterm. ${ }^{12}$ We handled this finding in our study by means of a 1:1 matched comparison of the prenatal-exposure group and the control group as assessed in the same country with the same Bayley edition and by calculating correlations and regression models only on Bayley II scores.

Cardiac evaluation was performed at 36 months of age to avoid having to use sedation for the tests, which consisted of 12-lead electrocardiography and a detailed echocardiographic examination. Standard views and measurements were performed according to the guidelines of the American Society of Echocardiography. ${ }^{13,14}$ Details regarding the echocardiographic protocol are provided in the Methods section in the Supplementary Appendix.

\section{STATISTICAL ANALYSIS}

We used descriptive statistics to describe maternal oncologic data, results of the health questionnaires, and clinical neurologic evaluations. We compared between-group background variables (child and maternal age, gestational age, sex, birth weight, race or ethnic background, maternal height and weight, parity, and parental education levels) using the Mann-Whitney $U$ test for continuous variables and the chi-square or Fisher's exact test for categorical data, depending on distribution characteristics, sample size, and number of categories. 
Raw cognitive scores were converted to standardized cognitive scores (not corrected for prematurity) according to normative data for each country in the Bayley manual. Univariate and multivariate linear regression models were used to look at the relationship between gestational age and cognitive outcome. Pearson correlations were used to investigate the relationship between cognitive outcome and parental education levels or the number of chemotherapy cycles. The relationship between cognitive outcome and the estimated fetal dose of radiation was investigated by means of Spearman's rank-correlation coefficient (rho). We used the Wilcoxon signed-rank test to compare cognitive scores and analysis of variance to adjust for covariates.

Electrocardiographic measurements were interpreted by an experienced cardiologist. All echocardiographic measurements were obtained in three cardiac cycles and averaged. When appropriate, measurements were corrected for bodysurface area, and $z$ scores were calculated. Independent sample t-tests were used to compare echocardiographic measurements and $\mathrm{z}$ scores in the two study groups.

A two-sided $\mathrm{P}$ value of less than 0.05 was considered to indicate statistical significance for all analyses. Up to six significant results could be expected on the basis of chance alone, given the plan to perform 110 subgroup analyses.

\section{RESULTS}

\section{CHARACTERISTICS OF THE CHILDREN}

A total of 129 children (including four pairs of twins) were included in the prenatal-exposure group: 103 from Belgium, 8 from the Netherlands, 10 from Italy, and 8 from the Czech Republic. These children were matched with 129 control children: 111 from Belgium, 10 from Italy, and 8 from the Czech Republic. Children in the two study groups were exa mined at a median age of 22 months (range, 12 to $42 ; \mathrm{P}=0.15$ ) and were equally distributed according to sex $(\mathrm{P}=0.32)$ (Table 1). Of the 129 children, data were in who were tested at the age of 18 months and for 54 children and matching controls who were tested at the age of 36 months; a total of 48 children were tested at both time points.

At the time of the cancer diagnosis, the median maternal age was 33 years (range, 19 to 42), and the median gestational age was 17.7 weeks (range 1.0 to 37.5). During pregnancy, 96 children (74.4\%) were exposed to chemotherapy (alone or in combination with other treatments), 11 (8.5\%) to radiotherapy (alone or in combination), $13(10.1 \%)$ to surgery alone, $2(1.6 \%)$ to other drug treatments, and 14 (10.9\%) to no treatment (Table 2). A total of 391 cycles of chemotherapy were administered to 93 women (including 3 carrying twins). Additional details regarding the maternal cancer type and specific treatments are provided in Tables S1 and S2 in the Supplementary Appendix.

\section{PERINATAL OUTCOME}

Children in the prenatal-exposure group were born at a median gestational age of 36 weeks (range, 27 to 41). A total of 79 children (61.2\%) were born preterm, as compared with a general percentage of preterm births of 6.8 to $8.0 \%$ in the participating countries. ${ }^{15}$ (Gestational age was not specified for the control group, since children in the prenatal-exposure group were matched with controls according to gestational age at birth.) Eleven children were born between 27.0 and 31.9 weeks (very preterm), 16 between 32.0 and 33.9 weeks (moderately preterm), 52 between 34.0 and 36.9 weeks (late preterm), and 50 at 37 weeks or later (full term). The number and type of congenital malformations were similar to those in the general population (Table S8 in the Supplementary Appendix), and the results of neonatal neurologic examinations were normal. Among 127 children for whom data on birth weight were available, the median birth weight was $2705 \mathrm{~g}$ (range, 720 to 4690). A birth weight below the 10th percentile (i.e., the definition of small for gestational age) was reported in 28 of 127 children in the prenatal-exposure group and in 19 of 125 children in the control group $(22.0 \%$ and $15.2 \%$, respectively; $\mathrm{P}=0.16$ ). More specifically, status as small for gestational age was reported in 24 of 95 children (25\%) who were exposed to chemotherapy and for whom data were available and in 4 of 11 children (36\%) who were exposed to radiotherapy (Table 2).

\section{GROWTH AND GENERAL HEALTH}

The incidence of medical problems and the need for surgery or medical care were similar in the two study groups (Table S10 in the Supplementary Appendix). However, one child in the prenatal-exposure group was excluded from further 


\begin{tabular}{|c|c|c|c|}
\hline Characteristic & $\begin{array}{c}\text { Prenatal-Exposure } \\
\text { Group } \\
(\mathrm{N}=129)\end{array}$ & $\begin{array}{l}\text { Control } \\
\text { Group } \\
(\mathrm{N}=129) *\end{array}$ & P Value \\
\hline Median age (range) - mo & $22(12-42)$ & $22(12-42)$ & 0.15 \\
\hline Median gestational age (range) - wk & $36(27-41)$ & $36(27-41)$ & 1.00 \\
\hline Median birth weight (range) $-\mathrm{g}$ & $2705(720-4690)$ & $2755(1100-4905)$ & 0.50 \\
\hline Median maternal age (range) $-\mathrm{yr}$ & $33.4(19.6-43.5)$ & $31.0(20.6-40.2)$ & 0.001 \\
\hline Sex-no. (\%) & & & 0.32 \\
\hline Male & $60(46.5)$ & $68(52.7)$ & \\
\hline Female & $69(53.5)$ & $61(47.3)$ & \\
\hline Race - no. (\%) † & & & 0.12 \\
\hline White & $108(83.7)$ & $106(82.2)$ & \\
\hline Black & $11(8.5)$ & $3(2.3)$ & \\
\hline Other & $7(5.4)$ & $7(5.4)$ & \\
\hline Unknown & $3(2.3)$ & $13(10.1)$ & \\
\hline \multicolumn{4}{|c|}{ Highest level of education of parents - no. (\%) } \\
\hline Mother & & & $<0.001$ \\
\hline No education & 0 & 0 & \\
\hline Primary school & $3(2.3)$ & 0 & \\
\hline Secondary school & $50(38.8)$ & $18(14.0)$ & \\
\hline Bachelor's degree & $29(22.5)$ & $29(22.5)$ & \\
\hline Master's degree or higher & $41(31.8)$ & $59(45.7)$ & \\
\hline Unknown & $6(4.7)$ & $23(17.8)$ & \\
\hline Father or female coparent & & & 0.02 \\
\hline No education & $1(0.8)$ & 0 & \\
\hline Primary school & $3(2.3)$ & 0 & \\
\hline Secondary school & $52(40.3)$ & $29(22.5)$ & \\
\hline Bachelor's degree & $30(23.3)$ & $25(19.4)$ & \\
\hline Master's degree or higher & $36(27.9)$ & $51(39.5)$ & \\
\hline Unknown & $7(5.4)$ & 24 (18.6) & \\
\hline
\end{tabular}

* Control groups for the cognitive and cardiac examinations include many of the same children. However, some controls are different because of the different matching criteria for cognitive and cardiac results. Listed here are the baseline characteristics for the control group that was evaluated for cognitive development, general health, and customized growth curves.

$\dagger$ Race was self-reported by the parents.

$\checkmark$ The highest level of education is presented according to the European educational system. A bachelor's degree is earned at both traditional universities and nonuniversity institutions of higher education and requires between three and four years of full-time study. A master's degree is earned at university and requires 1 to 2 years of full-time study after a bachelor's degree.

analyses because of the diagnosis of a syndromal entity. This case has been described in detail previously. ${ }^{8}$

Registered biometric data showed similar between-group results for weight, height, and head circumference (data not shown). ${ }^{16}$ In the sub- group of children who were small for gestational age and whose mothers received chemotherapy, we observed a catch-up weight at the time of testing in 14 of 22 children (63.6\%); of these children, 17 were tested at 18 months and 5 were tested at 36 months, with unknown results in 2 children. 
Table 2. Cancer Treatment during Pregnancy for All Children and Those Categorized as Small for Gestational Age.

\begin{tabular}{|c|c|c|}
\hline Cancer Treatment & $\begin{array}{c}\text { All } \\
\text { Children } \\
\text { (N=129) } \\
\text { no. (\%) }\end{array}$ & $\begin{array}{l}\text { Small for } \\
\text { Gestational Age } \\
\qquad(\mathrm{N}=\mathbf{2 8}) *\end{array}$ \\
\hline Surgery & $13(10.1) \dagger$ & $2(15.4)$ \\
\hline Chemotherapy & $41(31.8)$ & $11(27.5)$ \\
\hline Radiotherapy & $1(0.8)$ & 0 \\
\hline Surgery and chemotherapy & $48(37.2) \dagger$ & $10(20.8)$ \\
\hline Surgery and radiotherapy & $3(2.3)$ & $1(33.3)$ \\
\hline Chemotherapy and radiotherapy & $3(2.3) \dagger$ & $2(66.7)$ \\
\hline Surgery, chemotherapy, and radiotherapy & $4(3.1)$ & $1(25.0)$ \\
\hline Trastuzumab & $1(0.8)$ & 0 \\
\hline Interferon $\beta$ & $1(0.8)$ & $1(100.0)$ \\
\hline No treatment & 14 (10.9) & 0 \\
\hline
\end{tabular}

* Data regarding birth weight were available for 127 children in the prenatalexposure group; no data were available for 1 child in the chemotherapy subgroup and for 1 child in the no-treatment subgroup. Shown are the percentages of children who were small for their gestational age as compared with all children who were exposed to each cancer treatment.

$\uparrow$ One pair of twins was exposed to surgery alone, two pairs of twins to surgery and chemotherapy, and one pair of twins to chemotherapy and radiotherapy.

\section{COGNITIVE DEVELOPMENT}

We compared the children in the two study groups for several background variables with respect to cognitive development (Table 1). There were no significant between-group differences in gestational age, test age, sex, or race. A significant difference was found for parents' level of education, since the parents of children in the control group were on average more highly educated than those of children in the prenatal-exposure group $(\mathrm{P}<0.001$ for mothers and $\mathrm{P}=0.02$ for fathers or female coparents). Maternal and paternal education levels were related to the cognitive outcome on the Bayley II $(\mathrm{r}=0.303[\mathrm{P}=0.001]$ for mothers and $\mathrm{r}=0.211[\mathrm{P}=0.03]$ for fathers) in the prenatalexposure group but not in the control group $(r=0.020[\mathrm{P}=0.84]$ and $\mathrm{r}=0.009[\mathrm{P}=0.93]$, respectively). In further analyses, parental education levels were included as a covariate.

Sex differences in cognitive outcome were found on the Bayley II and III scales. A total of 130 girls for whom data were available had a was significantly higher than that for 128 boys (median score, 97.5; range, 50 to $145 ; \mathrm{P}=0.001$ ), even after adjustment for study group. Gesta-
Figure 2 (facing page). Cognitive Outcome.

Panel A shows the scores for cognitive outcome on the Bayley Scales of Infant Development, second edition (Bayley II), according to gestational age at birth for 119 children in the prenatal-exposure group and a matching number of children in the control group. (A total of 10 children with Bayley III scores are not included in this analysis, since pooling of data that were scored with the two versions was inappropriate because of differences in scoring method.) Standard scores on the Bayley II range from 50 to 150, with higher scores indicating more advanced development; the mean $( \pm S D)$ score is $100 \pm 15$, and a score of less than 85 indicates a developmental delay. Mean values (as calculated by linear regression) are indicated by a solid line for the prenatal-exposure group and a dashed line for the control group. Panel B shows the distribution of the results of the last performed Bayley Scales (II or III) for 129 children in the prenatal-exposure group and a matching number of children in the control group. Scores in the prenatal-exposure group are represented by a solid line, and scores in the control group by a dashed line. By definition, the area under the curve of a probability density function sums to 1 . Panel $C$ shows cognitive outcome (as reported as the median Bayley II or III score) for subgroups of children according to the cancer treatment received by their mothers. The horizontal bars indicate the simple range of scores. Each child in the prenatalexposure group is matched with a child in the control group according to gestational age at birth and test age. Some children had prenatal exposure to a combination of treatment options (e.g., taxanes plus platinum derivatives) and therefore are included in more than one group. Panel D shows Bayley II scores for 87 children in the prenatal-exposure group in relation to the number of chemotherapy cycles administered during pregnancy. Panel E shows Bayley II scores for 11 children in relation to the estimated fetal dose of radiation exposure (expressed in milligrays) during pregnancy. Two children (twins) had the same score, which appears as one data point.

tional age was related to the cognitive score in the two study groups (Fig. 2A). A univariate linear regression model showed that for all 238 children scale, the average cognitive score tended to increase by 2.9 points for each additional week in gestational age at birth $(95 \%$ confidence interval [CI], 2.2 to 3.7; $\mathrm{P}<0.001$ ), as calculated from an increase of 2.8 points ( $95 \% \mathrm{CI}, 1.6$ to 3.9 ) in the prenatal-exposure group and of 3.1 points $(95 \%$ CI, 2.0 to 4.1) in the control group $(\mathrm{P}<0.001$ for both comparisons). In a regression model with gestational age, study group, and the interaction between gestational age and study group as predictors of cognitive outcome, the interaction term was not significant $(\mathrm{P}=0.68)(\mathrm{P}=0.05$ for 


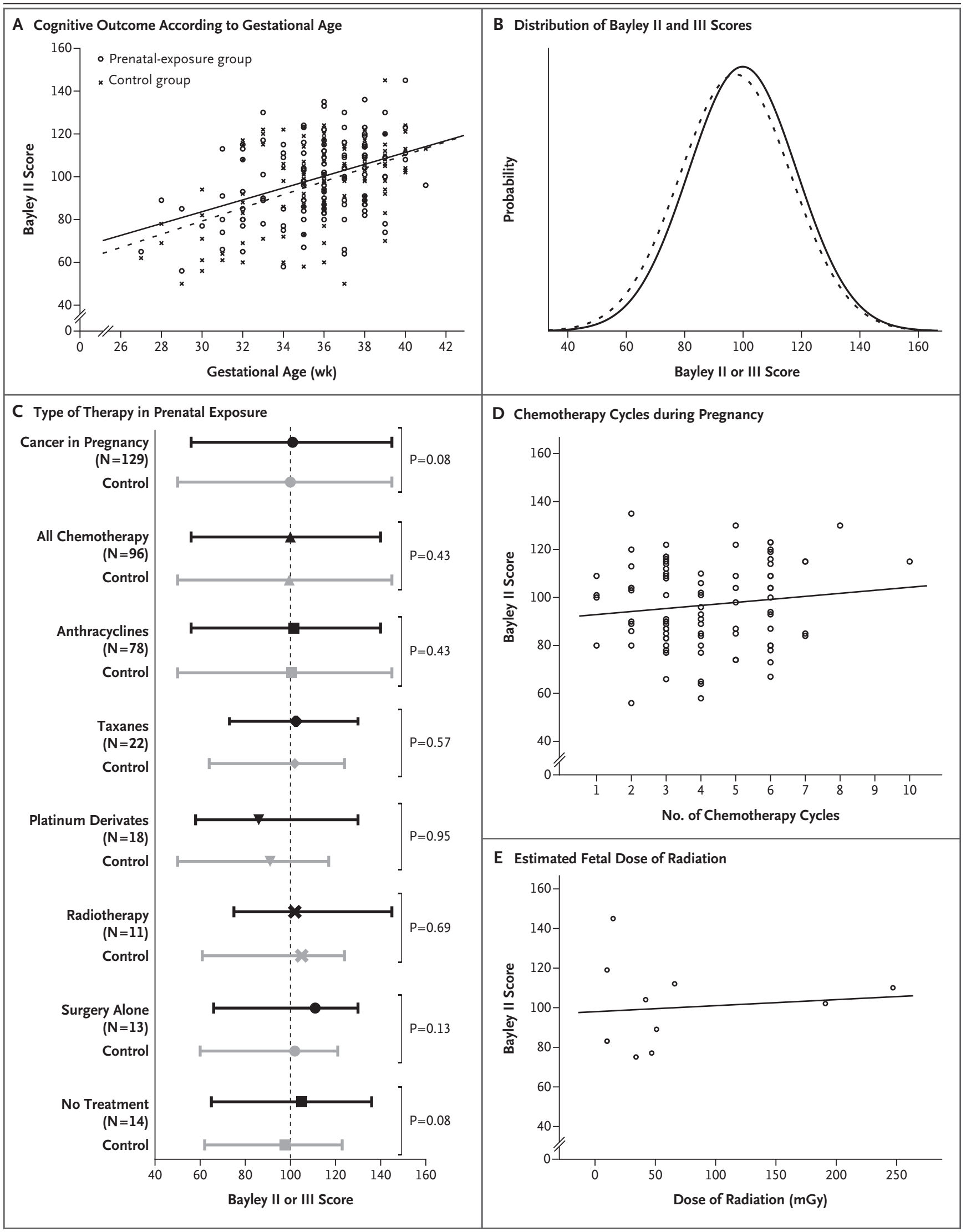




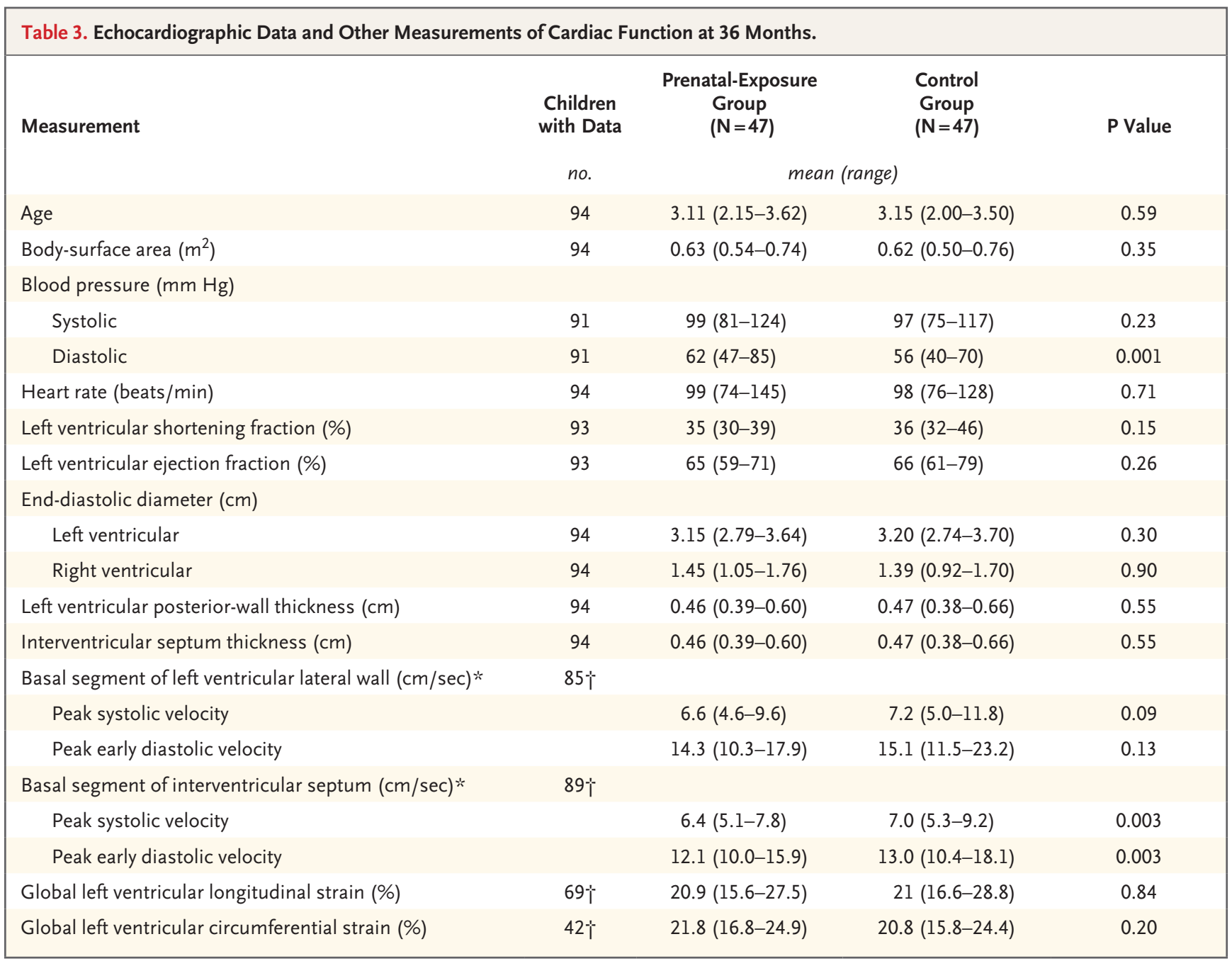

$*$ Measurements were obtained with the use of tissue Doppler imaging.

$\uparrow$ Data were not included when tracking could not be performed owing to poor image quality.

gestational age and $\mathrm{P}=0.62$ for study group). After adjustment for sex, test age, country, parental education level, and race, there was an average increase of 2.2 points (95\% CI, 1.5 to $3.0 ; \mathrm{P}<0.001$ ) for each additional week of gestational age. However, sex and gestational age were not included as covariates in later analyses because they were equally distributed in the two study groups.

There were no significant between-group differences in cognitive development according to the children's country of origin (Fig. S1 in the Supplementary Appendix). Most of the children in the two study groups had normal cognitive development (Fig. 2B), with no significant betweengroup differences $(\mathrm{P}=0.08)$. Cognitive outcome was not significantly different between children who were exposed to chemotherapy and children in the control group ( $\mathrm{P}=0.43$ ) (Fig. $2 \mathrm{C}$ ). Even after adjustment for parental education levels, the between-group difference was not significant $(\mathrm{P}=0.52)$. As compared with matched controls in subanalyses, there were no significant differences in cognitive outcome for children who were exposed to radiotherapy, surgery alone, or no treatment during pregnancy and no differences according to the type of chemotherapy (anthracyclines, taxanes, and platinum derivatives) (Fig. 2C). Cognitive outcome on the Bayley II scale was not related to the number of chemotherapy cycles that were administered during pregnancy $(\mathrm{r}=0.126$, $\mathrm{P}=0.24$ ) (Fig. 2D) or to the estimated fetal dose of radiation ( $r=0.110, \mathrm{P}=0.75)$ (Fig. $2 \mathrm{E})$. The inclusion of the single child with a syndromal entity in the analysis instead of another child in the prenatal-exposure group with the same gestational age, test age, sex, country, and ma- 
ternal disease did not change the results with respect to cognitive development (data not shown).

\section{CARDIAC EVALUATION AT 36 MONTHS}

Cardiac function was assessed in 50 of 54 children in the prenatal-exposure group at the age of 36 months with the use of electrocardiography and echocardiography. (Data for 3 children were excluded owing to a lack of cooperation during the examinations, so 47 children were included in the analysis.) Data were compared with those of 47 children in the control group who were matched for age and sex. There were no significant between-group differences in age, body-surface area, heart rate, or blood pressure. On echocardiographic examination, no structural abnormalities were detected in any of the children (Table 3). All measures of cardiac-chamber dimensions and wall thickness were within normal ranges, and there were no significant between-group differences in ejection fraction, fractional shortening, or values for global longitudinal strain and circumferential strain. There also were no significant between-group differences in echocardiographic measurements of diastolic function. We observed small but significant betweengroup differences in tissue Doppler imaging measurements of the basal segment of the interventricular septum (with higher mean peak systolic and early diastolic velocities in the control group [ $\mathrm{P}=0.003$ for both comparisons]) but not in measurements of the left ventricular lateral wall. These differences in tissue Doppler velocities were not present in the 26 children who were exposed to anthracyclines, as compared with the control group (Table S16 in the Supplementary Appendix).

\section{DISCUSSION}

In this multicenter, prospective case-control study involving 129 children and their matched controls, we documented the effects of prenatal exposure to maternal cancer and cancer treatment on general health, prenatal and postnatal growth, cognitive development, and cardiac structure and function. Although the incidence of preterm delivery in the prenatal-exposure group was high (61.2\%), the development of these children at a median age of 22 months was normal for their gestational age at birth. In subgroup analyses, the development of 96 children who were exposed to chemotherapy and of the 11 children who were exposed to radiotherapy did not differ significantly from that of children in the control group.

Health problems and cognitive outcomes were similar in the prenatal-exposure group and the control group, a finding that is consistent with the results of previous studies. ${ }^{3,5,8,17}$ Cognitive outcomes seemed to have no correlation with the number of chemotherapy cycles. Also, the negative prognostic effect of prematurity on cognitive development was confirmed, and the effect was similar in the two study groups.

Children who were small for their gestational age were more frequently born to mothers with cancer during pregnancy than were children in the control group ( $22.0 \%$ vs. $15.2 \%)$; however, the difference was not significant. Earlier studies have highlighted the finding that the proportion of children who are small for their gestational age is increased in pregnancies complicated by maternal cancer. ${ }^{18}$ Such children are at increased risk for perinatal complications and death. ${ }^{19}$ Among these children, factors associated with a small size at birth include a compromised placental supply of nutrients and oxygen to the fetus (in 80 to $90 \%$ of all cases), altered metabolic adaptations of pregnancy, and chronic inflammation. ${ }^{20-23}$ It has been hypothesized that several of these factors are present in a pregnancy complicated by cancer. (Further information is provided in Section 3 in the Supplementary Appendix.)

Among children who were evaluated at 36 months by means of electrocardiography and echocardiography, cardiac structure and function were normal. This observation is consistent with previous studies in which cardiac function was evaluated in fetuses, newborns, and older children., ${ }^{4,24}$ In our study, conventional measurements of systolic and diastolic function and tissue Doppler velocities and myocardial strain measurements were all within normal range, and no significant between-group differences were found. A subanalysis of 26 children with exposure to anthracyclines during pregnancy also revealed no significant between-group differences. In this subgroup of children, there were no signs of early cardiac remodeling, with normal wall thicknesses and chamber dimensions, and all measurements of systolic and diastolic function were within normal ranges. In the entire study group, we found 
small differences between the prenatal-exposure group and the control group in tissue Doppler velocities in the basal portion of the interventricular septum. We believe these findings are clinically irrelevant, since the measurements were within the normal range.

The reassuring outcome may be explained by the timing of chemotherapy administration and the role of the placenta. All cycles of chemotherapy in this series were administered after the first trimester of pregnancy. The period before a gestational age of 10 weeks is the most vulnerable, since organogenesis is occurring during this period. Administration of chemotherapy after the first trimester does not result in an increased rate or additional types of congenital malformations. ${ }^{17,18,25}$ Both the placental brush border and the basolateral membrane contain active drug transporters that influence fetal drug exposure. Apart from the drug-transporter affinity, transplacental passage depends on lipid solubility, molecular weight, binding capacity to plasma proteins, and placental metabolism of the agents. These regulatory mechanisms result in plasma drug levels that are lower in the fetus than in the mother, although variation in transplacental passage ranges from $0 \%$ for taxanes to $57 \%$ for carboplatin. 1,2,26,27

Our study has some limitations. Our results cannot be extrapolated to all chemotherapeutic drugs, especially new targeted drugs. In addition, the follow-up period was too short to document long-term cardiotoxicity and neurocogni- tive problems that may become more apparent later in life.

In conclusion, children who had prenatal exposure to cancer and the associated stress, imaging studies, and treatments had normal development during testing at 18 months, 36 months, or both. In particular, chemotherapy had no clear adverse effects on postnatal growth or on cognitive or cardiac function. Our data suggest that the diagnosis of cancer during pregnancy is not necessarily an indication to terminate the pregnancy. Although caution is always indicated, treatment of the maternal cancer in the second trimester or later may not be harmful to the fetus. Pregnant women may be informed that the likelihood of prematurity is higher than that in the general population, but among preterm babies, the child is unlikely to have unique problems more serious than those of preterm babies born of women without cancer during pregnancy.

Supported by Research Foundation-Flanders (clinical investigator grant to Dr. Amant and fellowships to Ms. Vandenbroucke and Dr. Verheecke), Stichting tegen Kanker, Belgian Cancer Plan (Ministry of Health), and KU Leuven; and by a clinical research grant from the University Hospitals Leuven (to Dr. Van Calsteren).

Disclosure forms provided by the authors are available with the full text of this article at NEJM.org.

We thank Ilse De Croock, Jana Dekrem, Griet De Mulder, Ilse Denolf, Tom Depuydt, Liesbeth Leemans, Caroline Sterken, Marie-Astrid Van Hoorick, Diane Wolput, and Heidi Wouters (UZ Leuven, Belgium); Griet Van der Perre (KU Leuven, Belgium); Camilla Fontana, Fabio Mosca, Sofia Passera, Silvia Pisoni, and Giovanna Scarfone (Fondazione IRCCS Cà Granda Ospedale Maggiore Policlinico, Milan); Carolina Schröder (University Medical Center Groningen, the Netherlands); and Livia Kapusta, Petronella Ottevanger, and Michel Willemsen (Radboud University Medical Center Nijmegen, the Netherlands).

The authors' full names and academic degrees are as follows: Frédéric Amant, M.D., Ph.D., Tineke Vandenbroucke, M.Sc., Magali Verheecke, M.D., Monica Fumagalli, M.D., Michael J. Halaska, M.D., Ph.D., Ingrid Boere, M.D., Ph.D., Sileny Han, M.D., Ph.D., Mina Mhallem Gziri, M.D., Ph.D., Fedro Peccatori, M.D., Ph.D., Lukas Rob, M.D., Ph.D., Christianne Lok, M.D., Ph.D., Petronella Witteveen, M.D., Ph.D., Jens-Uwe Voigt, M.D., Ph.D., Gunnar Naulaers, M.D., Ph.D., Lore Vallaeys, M.D., Frank Van den Heuvel, Ph.D., Lieven Lagae, M.D., Ph.D., Luc Mertens, M.D., Ph.D., Laurence Claes, Ph.D., and Kristel Van Calsteren, M.D., Ph.D., for the International Network on Cancer, Infertility, and Pregnancy (INCIP)

The authors' affiliations are as follows: the Department of Gynecologic Oncology, University Hospitals Leuven and Department of Oncology, Katholieke Universiteit Leuven (F.A., T.V., M.V., S.H.), Departments of Cardiology (J.-U. V.), Pediatrics (G.N., L.V., L.L.), and Obstetrics (K.V.C.), University Hospitals Leuven, and the Department of Growth and Regeneration (G.N., L.L., K.V.C.) and the Faculty of Psychology and Educational Sciences (L.C.), Katholieke Universiteit Leuven, Leuven, and the Department of Obstetrics, Cliniques Universitaires St. Luc, Brussels (M.M.G.) - all in Belgium; Neonatal Intensive Care Unit, Fondazione IRCCS Ca' Granda Ospedale Maggiore Policlinico Milano, Università degli Studi di Milano (M.F.) and Fertility and Reproduction Unit, European Institute of Oncology (F.P.) - both in Milan; the Department of Obstetrics and Gynecology, Charles University, Prague, Czech Republic (M.J.H., L.R.); the Department of Medical Oncology, Erasmus Medical Center Cancer Institute, Rotterdam (I.B.), Center for Gynecologic Oncology Amsterdam, Antoni van Leeuwenhoek-Netherlands Cancer Institute, Amsterdam (F.A., C.L.), and the Department of Medical Oncology, University Medical Center Utrecht Cancer Center, Utrecht (P.W.) - all in the Netherlands; the Departments of Physics, Nuclear Physics, and Medical Physics, University of Oxford, Oxford, United Kingdom (F.V.H.); and the Department of Cardiology, Hospital for Sick Children, University of Toronto, Toronto (L.M.). 
REFERENCES

1. Van Calsteren K, Verbesselt R, Devlieger $\mathrm{R}$, et al. Transplacental transfer of paclitaxel, docetaxel, carboplatin, and trastuzumab in a baboon model. Int J Gynecol Cancer 2010;20:1456-64.

2. Van Calsteren K, Verbesselt R, Beijnen J, et al. Transplacental transfer of anthracyclines, vinblastine, and 4-hydroxycyclophosphamide in a baboon model. Gynecol Oncol 2010;119:594-600.

3. Avilés A, Neri N. Hematological malignancies and pregnancy: a final report of 84 children who received chemotherapy in utero. Clin Lymphoma 2001;2:173-7. 4. Avilés A, Neri N, Nambo MJ. Longterm evaluation of cardiac function in children who received anthracyclines during pregnancy. Ann Oncol 2006;17:286-8. 5. Hahn KM, Johnson PH, Gordon N, et al. Treatment of pregnant breast cancer patients and outcomes of children exposed to chemotherapy in utero. Cancer 2006;107:1219-26.

6. Murthy RK, Theriault RL, Barnett $\mathrm{CM}$, et al. Outcomes of children exposed in utero to chemotherapy for breast cancer. Breast Cancer Res 2014;16:500.

7. Luis SA, Christie DR, Kaminski A, Kenny L, Peres MH. Pregnancy and radiotherapy: management options for minimising risk, case series and comprehensive literature review. J Med Imaging Radiat Oncol 2009;53:559-68.

8. Amant F, Van Calsteren K, Halaska $\mathrm{MJ}$, et al. Long-term cognitive and cardiac outcomes after prenatal exposure to chemotherapy in children aged 18 months or older: an observational study. Lancet Oncol 2012;13:256-64.

9. van der Giessen PH. Peridose, a software program to calculate the dose outside the primary beam in radiation therapy. Radiother Oncol 2001;58:209-13.

10. Bayley N. Bayley scales of infant development, 2nd ed. San Antonio, TX: Psychological Corporation, 1993.
11. Bayley N. Bayley scales of infant and toddler development, 3rd ed: administration manual. San Antonio, TX: Harcourt Assessment, 2005.

12. Lowe JR, Erickson SJ, Schrader R, Duncan AF. Comparison of the Bayley II Mental Developmental Index and the Bayley III Cognitive Scale: are we measuring the same thing? Acta Paediatr 2012; 101(2):e55-e58.

13. Lai WW, Geva T, Shirali GS, et al. Guidelines and standards for performance of a pediatric echocardiogram: a report from the Task Force of the Pediatric Council of the American Society of Echocardiography. J Am Soc Echocardiogr 2006;19:1413-30.

14. Lopez L, Colan SD, Frommelt PC, et al. Recommendations for quantification methods during the performance of a pediatric echocardiogram: a report from the Pediatric Measurements Writing Group of the American Society of Echocardiography Pediatric and Congenital Heart Disease Council. J Am Soc Echocardiogr 2010;23:465-95.

15. Blencowe $\mathrm{H}$, Cousens S, Oestergaard $\mathrm{MZ}$, et al. National, regional, and worldwide estimates of preterm birth rates in the year 2010 with time trends since 1990 for selected countries: a systematic analysis and implications. Lancet 2012;379: 2162-72.

16. Roelants M, Hauspie R, Hoppenbrouwers K. References for growth and pubertal development from birth to 21 years in Flanders, Belgium. Ann Hum Biol 2009; 36:680-94.

17. Cardonick EH, Gringlas MB, Hunter K, Greenspan J. Development of children born to mothers with cancer during pregnancy: comparing in utero chemotherapyexposed children with nonexposed controls. Am J Obstet Gynecol 2015;212: e1-e8.

18. Van Calsteren K, Heyns L, De Smet F, et al. Cancer during pregnancy: an analysis of 215 patients emphasizing the obstetrical and the neonatal outcomes. J Clin Oncol 2010;28:683-9.

19. Cunningham FG. Fetal growth disorders. In: Cunningham FG, Leveno KJ, Bloom SL, et al., eds. Williams obstetrics. 23rd ed. New York: McGraw-Hill, 2010: 842-58.

20. Sankaran S, Kyle PM. Aetiology and pathogenesis of IUGR. Best Pract Res Clin Obstet Gynaecol 2009;23:765-77.

21. Rakers F, Bischoff S, Schiffner R, et al. Role of catecholamines in maternalfetal stress transfer in sheep. Am J Obstet Gynecol 2015 July 26 (Epub ahead of print).

22. Cotechini T, Graham CH. Aberrant maternal inflammation as a cause of pregnancy complications: a potential therapeutic target? Placenta 2015;36:960-6.

23. Newbern D, Freemark M. Placental hormones and the control of maternal metabolism and fetal growth. Curr Opin Endocrinol Diabetes Obes 2011;18:40916.

24. Gziri MM, Debiève F, De Catte L, et al. Chemotherapy during pregnancy: effect of anthracyclines on fetal and maternal cardiac function. Acta Obstet Gynecol Scand 2012;91:1465-8.

25. Loibl S, Han SN, von Minckwitz G, et al. Treatment of breast cancer during pregnancy: an observational study. Lancet Oncol 2012;13:887-96.

26. Mir O, Berveiller P, Ropert S, Goffinet F, Goldwasser F. Use of platinum derivatives during pregnancy. Cancer 2008;113: 3069-74.

27. Berveiller $\mathrm{P}$, Vinot $\mathrm{C}$, Mir O, et al. Comparative transplacental transfer of taxanes using the human perfused cotyledon placental model. Am J Obstet Gynecol 2012;207(6):e1-e7.

Copyright (C) 2015 Massachusetts Medical Society. 